\title{
Method Validation and Measurement Uncertainty Determination of Ethoxyquin and Antioxidant Activity in Paprika Seasonings and Paprika Sauces Frequently Consumed in South Korea
}

\author{
Gill-Woong Jang, Sun-Il Choi, Xionggao Han, Xiao Men, Hee-Yeon Kwon, Ye-Eun Choi, \\ Mi-Hye Park and Ok-Hwan Lee *(D)
}

Department of Food Science and Biotechnology, Kangwon National University, Chuncheon 24341, Korea; jkw4578@kangwon.ac.kr (G.-W.J.); docgotack89@kangwon.ac.kr (S.-I.C.); xionggao414@kangwon.ac.kr (X.H.); menxiaodonglei@kangwon.ac.kr (X.M.); sosakwon1@kangwon.ac.kr (H.-Y.K.); ye0538@kangwon.ac.kr (Y.-E.C.); mihye_p@kangwon.ac.kr (M.-H.P.)

* Correspondence: loh99@kangwon.ac.kr; Tel.: +82-33-250-6454; Fax: +82-33-259-5565

Received: 10 September 2020; Accepted: 27 September 2020; Published: 28 September 2020

\begin{abstract}
In this study, we investigated and validated a method for the quantitative analysis of ethoxyquin in paprika seasonings and sauces, which are frequently consumed in South Korea. Using this analytical method, we were able to confirm the presence of ethoxyquin under optimized high-performance liquid chromatography/photodiode array (HPLC-PDA) and liquid chromatography with tandem mass spectrometry conditions. Additionally, the antioxidant activity of ethoxyquin was assessed using the American Spice Trade Association values and its residual levels in paprika seasoning samples. The HPLC-PDA limits of detection and quantification for ethoxyquin were found to be 0.26 and $0.79 \mu \mathrm{g} / \mathrm{mL}$, and 0.33 to $1.00 \mu \mathrm{g} / \mathrm{mL}$, and the recoveries of ethoxyquin ranged from 86.75 to $101.70 \%$, with relative standard deviations ranging from $0.31 \%$ to $3.59 \%$. These results indicated that the analytical method in this study should be appropriate for the quantitative analysis of ethoxyquin in paprika seasoning and sauce matrices.
\end{abstract}

Keywords: ethoxyquin; method validation; measurement uncertainty; analytical method; antioxidant

\section{Introduction}

Approximately $40 \%$ of paprika (Capsicum annum L.) products are red, and the red color is attributed to $70-80 \%$ carotenoid complexes that are particularly rich in $\beta$-carotenoids and xanthophylls [1,2]. As paprika is mainly used as a food coloring agent, its market value depends in part on the strength and stability of its red color. However, many factors affect the loss of color of paprika during storage, and the most important one was the oxidation of carotenoids owing to exposure to heat, light, or oxygen [3]. Accordingly, various antioxidants have been used to prevent the oxidation of the paprika pigment, and ethoxyquin has been determined to present excellent antioxidant effects for the paprika pigment [4]. Ethoxyquin is a synthetic antioxidant, and Chen and Gutmanis have used it successfully to retain the color of paprika [5]. However, owing to the high interest of the research community in the effectiveness and risks of using ethoxyquin as an antioxidant, its use has been restricted in the European Community, and many studies have been conducted on the use, residuals, and analysis methods in different countries [6]. According to the USA regulation CFR 172.140, the use of ethoxyquin in chili powder and paprika should be limited to less than $100 \mu \mathrm{g} / \mathrm{g}$ [7]. The types of, and usage criteria for food additives depend on the characteristics of the food, culture, and food industry of each country, and therefore, it is necessary to reevaluate the safety of food additives for 
each country [8]. Thus, a validated method for the analysis of ethoxyquin in commonly consumed food matrices in Korea is necessary.

Various analytical methods, including gas chromatography, high-performance liquid chromatography with ultraviolet detection, and fluorescence detection have been used for the quantitative and qualitative analysis of ethoxyquin in paprika. However, the measurement uncertainties of these methods have not been reported to date $[9,10]$.

Therefore, in this study, we developed and validated a high-performance liquid chromatography/photodiode array (HPLC-PDA) method for the analysis of ethoxyquin in Korean paprika seasoning and sauce. Moreover, liquid chromatography with tandem mass spectrometry (LC-MS/MS) was used to identify the presence of ethoxyquin in paprika seasoning and sauce samples. Furthermore, the uncertainties of these methods were assessed for validation, and the ethoxyquin levels of paprika seasoning and sauce samples consumed in Korea were determined to confirm that the developed methods could be effectively used to analyze commercially available food samples.

\section{Materials and Methods}

\subsection{Reagents}

Ethoxyquin ( $\geq 90.0 \%$ ) was obtained from Santacruz (Dallas, TX, USA.), and acetone ( $\geq 99.3 \%)$, acetonitrile $(\geq 99.9 \%)$, ammonium acetate $(\geq 98.0 \%)$, methanol $(\geq 99.9 \%)$, and ethyl acetate $(\geq 99.6 \%)$ were acquired from J. T Baker (Philipsburg, NJ, USA)

\subsection{Food Materials}

We purchased 100 paprika samples (42 that contained paprika pigment and 58 that contained paprika) from South Korean grocery markets (Chuncheon). The sample of this study was analyzed by characteristics of the sauce added to food in the form of powder and flavored paprika seasoning and liquid form with viscosity.

\subsection{Optimization of the HPLC Analysis Conditions}

Ethoxyquin was analyzed using HPLC, and the analytical conditions were chosen in the following method. We evaluated the best results obtained using different analytical methods $[4,10,11]$. All experiments were performed using a C18 column and photodiode array (PDA) $(280 \mathrm{~nm})$ utilizing different eluent conditions and mobile phases. Then, the HPLC analytical parameters, such as the column and oven temperature, were evaluated, and the optimum conditions for the detection of ethoxyquin in paprika samples were determined. The sensitivity of the analytical method was assessed using the maximum allowable level of ethoxyquin in the USA. The assessment was performed using limits of detection (LOD) and limits of quantification (LOQ) values, which were calculated using the signal-to-noise ratios of 3.3 and 10, respectively.

We used a Waters 2695 HPLC (Waters Co., Milford, MA, USA) zsystem equipped with a column oven, an autosampler, a pump, and a Waters 996 PDA (Waters Co., Milford, MA, USA) detector. Chromatographic separation was performed using a $4.6 \mathrm{~mm} \times 250 \mathrm{~mm}$ Waters Sunfire C18 column (Waters Co., Milford, MA, USA) packed with $5.0 \mu \mathrm{m}$ particles. The column was maintained at $20^{\circ} \mathrm{C}$ and was isocratically eluted for $30 \mathrm{~min}$ with a mobile phase that comprised $0.01 \mathrm{M}$ ammonium acetate solution and acetonitrile mixture $(20: 80 \mathrm{v} / \mathrm{v})$. The mobile phase solutions were filtered using a Whatman (Amersham, England, UK) membrane filter with a pore size of $0.45 \mu \mathrm{m}$ and were degassed under vacuum. The flow rate and injection volume of the samples were set to be $1.0 \mathrm{~mL} / \mathrm{min}$ and $10 \mu \mathrm{L}$, respectively. Then, ethoxyquin was analyzed at the wavelength of $280 \mathrm{~nm}$ using the PDA detector.

\subsection{Optimization of Extraction Method and Sample Pretreatment}

Using an optimized HPLC-PDA assay, we determined the optimal method for the extraction of ethoxyquin from two matrices (paprika seasoning and sauce). The recovery rate was used to determine 
the optimal pretreatment method, and the pretreatment of samples used for the analysis of ethoxyquin was optimized using previously reported methods [1].

The modified method of Lee et al. was used to prepare the samples. Either $1 \mathrm{~g}$ seasoning sample or 2 g sauce sample was added to a conical tube, and then $20 \mathrm{~mL}$ ethyl acetate or $5 \mathrm{~mL}$ acetonitrile, respectively, was added to them. Afterward, the samples were stirred for $10 \mathrm{~min}$. Additionally, paprika sauce and paprika seasoning were diluted in $10 \mathrm{~mL}$ acetonitrile and $25 \mathrm{~mL}$ ethyl acetate, respectively.

\subsection{Method Validation}

\subsubsection{Validation of the HPLC Method}

The HPLC method for the detection of ethoxyquin in paprika seasoning and sauce was validated in terms of selectivity, linearity, precision, accuracy, LOD, and LOQ, according to the guidelines of the International Conference on Harmonization [11]. The matrix-matched curves were prepared by spiking food matrices with seven ethoxyquin standard solutions of concentrations ranging from 3.13 to $200 \mu \mathrm{g} / \mathrm{mL}$. During the development and verification of the analytical method, each validation run of the matrix-matched calibration curves was assessed to ensure that the sensitivity and linearity of the method were in agreement with the experimental observations and that no contaminants interfered. To evaluate the linearity of the HPLC method, we employed a calibration curve that was obtained using various concentrations of ethoxyquin. Furthermore, the LOD and LOQ of the HPLC method were determined for the analytes present in the paprika samples. The selectivity of the HPLC method was evaluated by confirming that none of the ingredients in the paprika samples could have interfered with ethoxyquin, the target analyte. The accuracy and precision of the HPLC method were determined using two matrices with three different ethoxyquin concentrations, namely 25.0,50.0, and $100.0 \mu \mathrm{g} / \mathrm{mL}$. The results were evaluated using intra-day (three repeats during one day) and inter-day (three repeats on three different days) experiments.

\subsubsection{Validation of the LC-MS/MS Method}

LC-MS/MS assays were performed using a QTRAP 4500 (AB Sciex, Framingham, MA, USA) HPLC system. Liquid chromatography separation was performed under the same conditions used for the HPLC-PDA analysis. The MS/MS data of ethoxyquin were detected in electrospray ionization (ESI) positive ion mode using the following selected reaction monitoring of transition m/z: $218.00 \rightarrow 160.00$ (collision energy, $47 \mathrm{eV}$ ), $218.00 \rightarrow 174.00$ (collision energy, $47 \mathrm{eV}$ ), and 218.00 $\rightarrow 160.00$ (collision energy, $29 \mathrm{eV}$ ). The optimized ESI parameters were as follows: spray voltage of $-4500 \mathrm{~V}$, sheath gas pressure of 25 arbitrary units, auxiliary gas pressure of 25 arbitrary units, and capillary temperature of $450{ }^{\circ} \mathrm{C}$.

\subsection{Functional Evaluation of Ethoxyquin As Antioxidant}

\subsubsection{Experimental Conditions}

The American Spice Trade Association (ASTA) values and residual ethoxyquin levels were determined using the method described by Osuna-Garcia et al. with some modifications, and paprika seasoning was used to evaluate the functionality of ethoxyquin. The ASTA color values are an indicator of the red color of red pepper published by the American Spice Trade Association and is an objective unit that evaluates the color of red pepper powder around the world. The ASTA values and residual ethoxyquin levels of paprika seasoning samples were determine to evaluate the browning of paprika during storage by adding $100 \mu \mathrm{g} / \mathrm{mL}$ ethoxyquin to paprika seasoning.

\subsubsection{ASTA Values}

The ASTA values of the paprika samples were determined using a spectrophotometer and were measured using the ASTA method 20.1 [12]. First, a $0.08 \mathrm{~g}$ ethoxyquin-free sample was added to a $100 \mathrm{~mL}$ volumetric flask that contained $100 \mathrm{~mL}$ acetone. The mixture was shaken and was allowed 
to rest overnight at $19-24{ }^{\circ} \mathrm{C}$. The ethoxyquin spiked sample was prepared by adding $100 \mu \mathrm{g} / \mathrm{mL}$ ethoxyquin to a paprika sample that was processed using the method described above. The color intensity of the samples was measured at the wavelength of $460 \mathrm{~nm}$ at 14-day intervals for 84 days. The ASTA value was calculated by the following equation: Absorbance at $460 \mathrm{~nm} \times 16.4 /$ sample weight (g).

\subsubsection{Measurement of Residual of Ethoxyquin}

The residual level of ethoxyquin was assessed using HPLC-PDA. First, $0.4 \mathrm{~g}$ samples were added to a $100 \mathrm{~mL}$ volumetric flask that contained $100 \mathrm{~mL}$ acetone. Then, the mixtures were shaken and allowed to rest overnight in the dark at $19-24^{\circ} \mathrm{C}$. The ethoxyquin spiked sample was prepared the same as above. Afterward, $10 \mathrm{~mL}$ aliquots were collected and the carotenoid pigments and ethoxyquin were concentrated under an $\mathrm{N}_{2}$ atmosphere. Subsequently, the samples were resuspended in $4 \mathrm{~mL}$ acetonitrile:methanol $(1: 1 \mathrm{v} / \mathrm{v})$ and were filtered through a $0.45 \mu \mathrm{m}$ membrane filter prior to being subjected to HPLC analysis.

\subsection{Measurement Uncertainty}

The uncertainty of the measurement for food dyes in soft drinks was determined using the method of Kim et al. using HPLC-PDA [13]. To measure uncertainty by the metrology approach, laboratory data such as precision studies, analytical process performance data, and quantification of ethoxyquin were required. Uncertainty was recorded from balances, volumetric measuring devices, sample preparation steps, reference materials, calibration curves, and instrumental factors. The expanded uncertainty (U) was obtained using the following equation:

$$
\mathrm{U}=\mathrm{k} \times \sqrt{U_{\text {prep }^{2}}{ }^{2}+U_{R M^{2}}+U_{s t d^{2}}+U_{c a l}^{2}+U_{\text {rep }}{ }^{2}}
$$

where $\mathrm{k}$ is the coverage factor, and $U_{\text {prep }}, U_{R M}, U_{s t d}, U_{c a l}$, and $U_{\text {rep }}$ are the uncertainty of the sample preparation, reference material, standard stock solution, calibration curve, and repeatability, respectively.

\section{Results and Discussion}

\subsection{Optimization of the HPLC Conditions}

To set up the HPLC analysis conditions, two analytical methods were compared, and the maximum absorption wavelength of ethoxyquin was $280 \mathrm{~nm}$. The method proposed by Vinas Cordoba and Sanchez-Pedreno consists of diluted water, acetonitrile, and ethyl acetate as mobile phases, and the presence of ethoxyquin in paprika samples was confirmed, but the baseline was not clear and the peak collapsed. In contrast, the baseline of the method described by He and Ackman with $0.01 \mathrm{M}$ ammonium acetate and acetonitrile as mobile phases was clear and the peak shape was excellent. Therefore, the method proposed by He and Ackman was used for the subsequent experiments. To select the best resolution column when various types of columns were used under the same HPLC conditions, we compared three different C18 columns: a Phenomenex Gemini $5 \mu$ C18 110A, Shiseido Capcell Pak C18 UG 120, and $4.6 \mathrm{~mm} \times 250 \mathrm{~mm}$ Waters Sunfire C18 column packed with $5.0 \mu \mathrm{m}$ particles. The retention times of the analytes were slightly different depending on the column. The Waters Sunfire C18 column presented the highest peak area of all columns and an excellent correlation coefficient, and therefore, it was selected for this study. The reason, presented in Figure 1, that the highest peak area appeared in the Waters Sunfire C18 column even though the same concentration was analyzed is because the efficiency of the Waters Sunfire C18 is column higher than that of other columns. In addition, heat was applied to the column to determine the effect of the retention time and peak shape of the analyte depending on the column temperature. When the isothermal temperatures of 20,30 , and $40^{\circ} \mathrm{C}$ were used, the retention time of ethoxyquin increased as the temperature increased, but there was no significant difference between the retention times are presented in Figure 2. Therefore, 
the maximum temperature of the ethoxyquin peak area was set to be $20^{\circ} \mathrm{C}$, which was considered to be the optimum temperature.

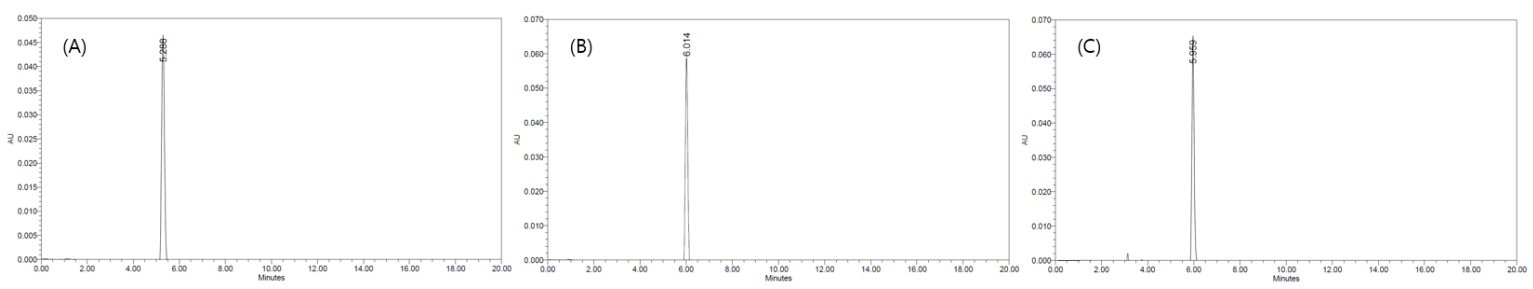

Figure 1. Change of high-performance liquid chromatography (HPLC) chromatograms of ethoxyquin by the C18 column varieties. (A) Phenomenex column, (B) Waters column, (C) Shiseido column.

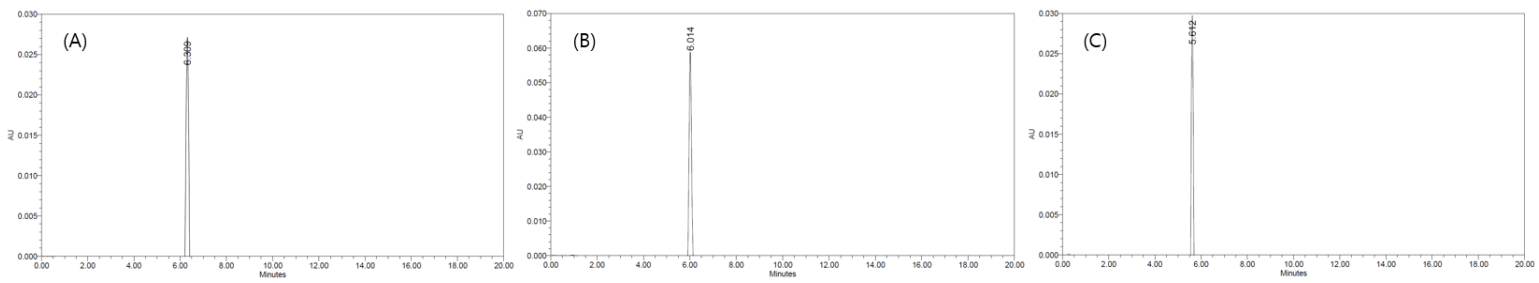

Figure 2. HPLC chromatograms of ethoxyquin in according to column varieties. (A) $20^{\circ} \mathrm{C},(\mathbf{B}) 30^{\circ} \mathrm{C}$, (C) $40{ }^{\circ} \mathrm{C}$.

\subsection{Optimization of the Extraction Method}

To select the optimal matrix pretreatment, $100 \mathrm{ppm}$ ethoxyquin was added to paprika seasoning and sauce samples. The extraction experiments were conducted according to the pretreatment methods described by Vinas Cordoba and Sanchez-Pedreno and Lee et al. Paprika seasoning and sauce samples were dissolved in hexane and ethyl acetate, respectively, for both pretreatment methods, but the amount of sample and volume of solvent were different.

The recovery rate of the paprika sauce sample pretreated using the method described by Vinas Cordoba and Sanchez-Pedreno was $90.65 \%$, which was appropriate according to the method validation guidelines. However, the recovery rate of the paprika seasoning sample pretreated using this method was $70.42 \%$, which was lower than that stipulated in the method validation guidelines.

The recovery rates of the paprika seasoning and sauce samples pretreated using the method proposed by Lee et al. were $41.32 \%$ and $21.85 \%$, respectively, which were too low according to the method validation guidelines. However, the recoveries of paprika seasoning and sauce samples pretreated by modifying the weight of the sample and the extraction conditions of the solvent through the modified Lee et al. were found to be $86.65 \pm 0.76$ and $90.53 \pm 3.60$, respectively. Thus, we selected the method proposed by Lee et al. for the preparation of samples, because the ethoxyquin recovery rates from paprika seasoning and sauce samples obtained using this method were higher than those obtained using the method described by Vinas Cordoba and Sanchez-Pedreno. The modified method is described in detail in Section 2.4.

After we modified the pretreatment process and selected the optimal pretreatment conditions, the ethoxyquin recovery rates of two food matrix samples pretreated using the optimized method ranged from $86.65 \%$ to $90.53 \%$. The three pretreatment methods are shown in Table 1 . 
Table 1. The original sample preparation method and the modified sample preparation method.

\begin{tabular}{|c|c|}
\hline Method & Sequence of Sample Preparation \\
\hline Vinas Cordoba \& Sanchez-Pedreno (1991) & $\begin{array}{l}\text { Weigh } 2 \mathrm{~g} \text { of the sauce sample or } 20 \mathrm{mg} \text { of the } \\
\text { seasoning sample, add } 20 \mathrm{~mL} \text { of hexane to the sauce } \\
\text { sample and } 20 \mathrm{~mL} \text { of ethyl acetate to the seasoning } \\
\text { sample, and stir for } 10 \mathrm{~min} \text {. The stirred sample was } \\
\text { filtered with a } 0.45 \mu \mathrm{m} \text { syringe filter, adjusted to the } \\
\text { mark using a pipette with hexane and ethyl acetate, } \\
\text { respectively, and then injected into HPLC-PDA for } \\
\text { analysis. }\end{array}$ \\
\hline Lee et al. (2002) & $\begin{array}{l}\text { Weigh } 2 \mathrm{~g} \text { of seasoning sample or } 2 \mathrm{~g} \text { of sauce sample, } \\
\text { add } 10 \mathrm{~mL} \text { of hexane and ethyl acetate to each of the } \\
\text { sauce sample and the seasoning sample, and stir for } \\
10 \text { min. The stirred sample was filtered through a } 0.45 \\
\mu \mathrm{m} \text { syringe filter and then injected into HPLC-PDA } \\
\text { for analysis. }\end{array}$ \\
\hline Modified Lee et al. (2002) & $\begin{array}{l}\text { Weigh } 2 \mathrm{~g} \text { of sauce sample or } 1 \mathrm{~g} \text { of seasoning sample, } \\
\text { add } 5 \mathrm{~mL} \text { of acetonitrile to the sauce sample, add } 20 \\
\mathrm{~mL} \text { of ethyl acetate to the seasoning sample, and stir } \\
\text { for } 10 \mathrm{~min} \text {. The stirred sauce sample and seasoning } \\
\text { sample were transferred to a } 10 \mathrm{~mL} \text { volumetric flask } \\
\text { and a } 25 \mathrm{~mL} \text { volumetric flask, respectively. The sauce } \\
\text { sample was acetonitrile and the seasoning sample } \\
\text { was adjusted to the mark of the flask with ethyl } \\
\text { acetate, and then injected into HPLC-PDA for } \\
\text { analysis. }\end{array}$ \\
\hline
\end{tabular}

\subsection{Method Validation}

\subsubsection{Validation of the HPLC-PDA Method}

In chromatography, selectivity refers to the extent to which a method can determine particular analytes in a matrix without interference from other components (Marin, Garcia, and Barbas). The chromatograms of standard ethoxyquin acquired using the HPLC-PDA method are presented in Figure 3. The HPLC-PDA method was analyzed to determine if other components present in paprika samples could interfere with the separation of ethoxyquin and to confirm that ethoxyquin was separated smoothly from the other components in the samples using the Waters Sunfire C18 column. Paprika samples were pretreated using the established pretreatment methods and ethoxyquin stock solutions were added to them to obtain diluted sample solutions with concentrations in the range of 3.13 to $200 \mu \mathrm{g} / \mathrm{mL}$. Then, the linearity of the HPLD-PDA method was analyzed, and it was confirmed that the determination coefficient of the calibration curve $\left(\mathrm{R}^{2}\right)$ ranged from 0.9999 to 1.0000 . The LOD and LOQ of the HPLC-PDA method are presented in Table 2, and the LOD of the paprika seasoning and sauce were found to be 0.26 and 0.33 $\mu \mathrm{g} / \mathrm{mL}$, and the LOQ of 0.79 and $1.00 \mu \mathrm{g} / \mathrm{mL}$, respectively. Therefore, the sensitivity of the HPLC-PDA method for the quantitative determination of ethoxyquin at levels below the maximum allowable limit in the USA was reasonable. 

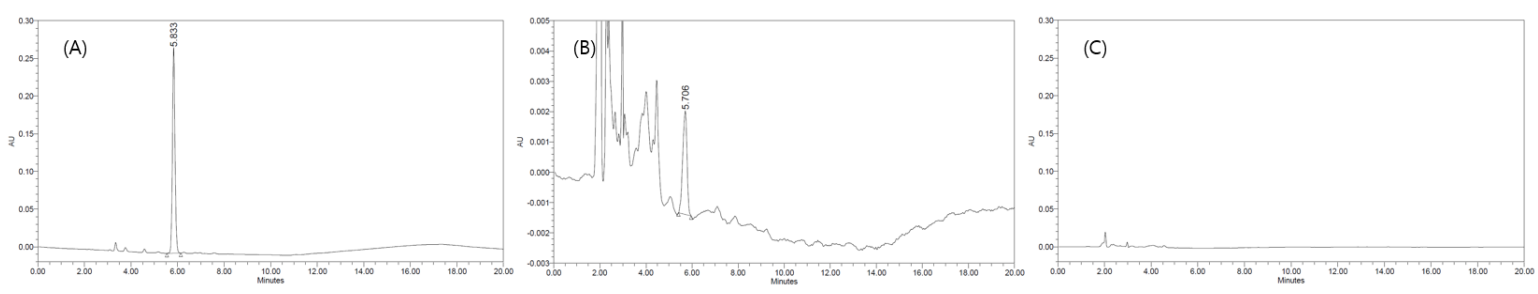

Figure 3. Chromatogram and spectrum of ethoxyquin using high-performance liquid chromatography/photodiode array (HPLC-PDA). (A) Ethoxyquin standard, (B) Ethoxyquin spiked in seasoning sample, (C) Blank sample.

Table 2. Correlation coefficients of the calibration curves, LOD and LOQ $(n=3)$.

\begin{tabular}{ccccccc}
\hline Matrix & $\begin{array}{c}\text { Range } \\
(\mu \mathrm{g} / \mathrm{mL})\end{array}$ & Slope & Intercept & $\begin{array}{c}\text { Correlation } \\
\text { Coefficient }\left(\mathbf{R}^{2}\right)\end{array}$ & $\begin{array}{c}\text { LOD } \\
(\mu \mathrm{g} / \mathrm{mL})\end{array}$ & $\begin{array}{c}\text { LOQ } \\
(\mu \mathrm{g} / \mathrm{mL})\end{array}$ \\
\hline $\begin{array}{c}\text { Paprika } \\
\text { seasoning }\end{array}$ & $3.13-200$ & $10597 \pm 8.8$ & $-2083 \pm 737.4$ & 1.0000 & 0.26 & 0.79 \\
\hline $\begin{array}{c}\text { Paprika } \\
\text { sauce }\end{array}$ & $3.13-200$ & $10518 \pm 12.5$ & $6031.9 \pm 352.9$ & 1.0000 & 0.33 & 1.00 \\
\hline
\end{tabular}

To ensure the reliability of the pretreatment method for the analysis of ethoxyquin, standard solutions of paprika seasoning and sauce with concentrations of 25,50 , and $100 \mu \mathrm{g} / \mathrm{mL}$ were added to food matrices, and the accuracy and precision of the pretreatment method were analyzed.

The analysis results are summarized in Table 3. The average recovery rates of the paprika seasoning and sauce samples were $101.70 \pm 112.45 \%$ and $86.75 \pm 2.18 \%$, respectively. The precision of the ethoxyquin analysis method was assessed using both intra- and inter-day relative standard deviations. The intra- and inter-day precisions of all samples ranged from $0.31 \%$ to $0.86 \%$ and from $1.68 \%$ to $3.03 \%$, respectively, for paprika sauce and from $1.18 \%$ to $3.60 \%$ and from $0.97 \%$ to $3.59 \%$, respectively, for paprika seasoning. Therefore the HPLC-PDA method presented excellent precision and accuracy for the detection of ethoxyquin from all sample matrices and at all concentrations.

Table 3. Recoveries of spiked ethoxyquin (three different concentrations) from paprika seasoning and paprika sauce samples $(n=3)$.

\begin{tabular}{|c|c|c|c|c|c|}
\hline Matrix & Analyte & & $\begin{array}{c}\text { Range } \\
(\mu \mathrm{g} / \mathrm{mL})\end{array}$ & RSD (\%) & Recovery (\%) \\
\hline \multirow{2}{*}{$\begin{array}{c}\text { Paprika } \\
\text { seasoning }\end{array}$} & \multirow{2}{*}{ Ethoxyquin } & Intra-day & $25-100$ & $1.18-3.60$ & $101.70-110.72$ \\
\hline & & Inter-day & $25-100$ & $0.97-3.59$ & $107.60-112.45$ \\
\hline \multirow{2}{*}{ Paprika sauce } & \multirow{2}{*}{ Ethoxyquin } & Intra-day & $25-100$ & $0.31-0.86$ & $87.87-89.64$ \\
\hline & & Inter-day & $25-100$ & $1.68-3.03$ & $86.75-90.13$ \\
\hline
\end{tabular}

\subsubsection{Validation of the LC-MS/MS Method}

The HPLC-PDA method is not sufficient to determine low-level additives in food matrices as they can interfere with HPLC-PDA measurements by the interference of other components that may be identified in the food matrices. Therefore, we used LC-MS/MS as a verification step to confirm the presence of ethoxyquin in food samples. The LOD, LOQ, and $\mathrm{R}^{2}$ values of the LC-MS/MS method for paprika seasoning were $0.71 \mu \mathrm{g} / \mathrm{mL}, 2.18 \mu \mathrm{g} / \mathrm{mL}$, and 1.000, respectively, and these results are listed in Table 4. 
Table 4. Correlation coefficients of the calibration curves, LOD and LOQ in paprika seasoning using LC-MS/MS.

\begin{tabular}{cccccccc}
\hline Matrix & Analyte & $\begin{array}{c}\text { Range } \\
(\mu \mathrm{g} / \mathrm{mL})\end{array}$ & Slope & Intercept & $\begin{array}{c}\text { Correlation } \\
\text { Coefficient }\left(\mathbf{R}^{2}\right)\end{array}$ & $\begin{array}{c}\text { LOD } \\
(\mu \mathrm{g} / \mathrm{mL})\end{array}$ & $\begin{array}{c}\text { LOQ } \\
(\mu \mathrm{g} / \mathrm{mL})\end{array}$ \\
\hline $\begin{array}{c}\text { Paprika } \\
\text { Seasoning }\end{array}$ & Ethoxyquin & $3.13-200$ & 880,667 & $5,557,842$ & 0.9877 & 0.71 & 2.18 \\
\hline
\end{tabular}

\subsection{Sample Collection and Monitoring the Residual Ethoxyquin level}

The validated method in this study was used to monitor the residual ethoxyquin levels in paprika seasoning and sauce samples that were purchased from domestic Korean markets. It is important to analyze samples purchased in the Korean market because among the products distributed in Korea, ethoxyquin, which is not allowed in Korea, may come in during the import process. Using the HPLC-PDA analysis method, the chromatographic peaks of the samples were discriminated by comparison with the PDA spectrum and retention time of an ethoxyquin standard sample. The presence of ethoxyquin was not detected in any of the 100 analyzed samples.

\subsection{Assessment of Antioxidant Properties of Ethoxyquin}

To assess the antioxidant activity of ethoxyquin, it was added to paprika seasoning samples. The ASTA values of, and residual ethoxyquin levels in the paprika seasoning samples were evaluated, and the results are listed in Table 5.

Table 5. Changes of the American Spice Trade Association (ASTA) values and residual level of ethoxyquin in paprika seasoning during storage.

\begin{tabular}{|c|c|c|c|c|c|}
\hline Storage Period & Sample & $\begin{array}{l}\text { ASTA Value } \\
(\text { Mean } \pm \text { SD) }\end{array}$ & $\begin{array}{c}\text { RSD }^{(2)} \\
(\%)\end{array}$ & $\begin{array}{l}\text { Residual } \\
\text { Level (\%) }\end{array}$ & $\begin{array}{c}\text { RSD } \\
(\%)\end{array}$ \\
\hline \multirow[t]{2}{*}{ Day 0} & $\begin{array}{l}\text { Ethoxyquin } \\
\text { spike }\end{array}$ & $66.13 \pm 2.54^{(1)}$ & 3.84 & 100 & 0 \\
\hline & Blank & $66.28 \pm 2.21$ & 3.34 & - & - \\
\hline \multirow[t]{2}{*}{ Day 14} & $\begin{array}{l}\text { Ethoxyquin } \\
\text { spike }\end{array}$ & $64.90 \pm 5.20$ & 8.02 & $99.49 \pm 1.89$ & 1.90 \\
\hline & Blank & $59.94 \pm 1.7$ & 2.96 & - & - \\
\hline \multirow[t]{2}{*}{ Day 28} & $\begin{array}{c}\text { Ethoxyquin } \\
\text { spike }\end{array}$ & $63.69 \pm 3.91$ & 6.14 & $97.31 \pm 0.62$ & 0.64 \\
\hline & Blank & $59.64 \pm 4.50$ & 7.55 & - & - \\
\hline \multirow[t]{2}{*}{ Day 42} & $\begin{array}{l}\text { Ethoxyquin } \\
\text { spike }\end{array}$ & $59.38 \pm 1.77$ & 2.98 & $96.55 \pm 0.42$ & 0.44 \\
\hline & Blank & $57.67 \pm 2.77$ & 4.80 & - & - \\
\hline \multirow[t]{2}{*}{ Day 56} & $\begin{array}{l}\text { Ethoxyquin } \\
\text { spike }\end{array}$ & $58.02 \pm 0.94 *$ & 1.62 & $94.67 \pm 0.53$ & 0.56 \\
\hline & Blank & $54.19 \pm 1.13$ & 2.08 & - & - \\
\hline \multirow[t]{2}{*}{ Day 70} & $\begin{array}{l}\text { Ethoxyquin } \\
\text { spike }\end{array}$ & $56.44 \pm 0.43 *$ & 0.76 & $92.47 \pm 0.81$ & 0.88 \\
\hline & Blank & $52.00 \pm 0.52$ & 0.99 & - & - \\
\hline \multirow[t]{2}{*}{ Day 84} & $\begin{array}{l}\text { Ethoxyquin } \\
\text { spike }\end{array}$ & $54.80 \pm 1.71$ * & 3.11 & $89.45 \pm 0.91$ & 1.02 \\
\hline & Blank & $49.82 \pm 0.94$ & 1.89 & - & - \\
\hline
\end{tabular}

(1) Values are Mean \pm S.D, $\mathrm{n}=3 .{ }^{(2)}$ Relative standard deviation. ${ }^{*}$ Mean $(\mathrm{n}=)$ significantly difference by T-test $(p<0.05)$. 
The ASTA values of the paprika seasoning samples spiked with ethoxyquin were lower than those of the control group, and the residual ethoxyquin levels in the spiked samples decreased as the storage period increased. It was hypothesized that ethoxyquin prevented the oxidation of the carotenoids in paprika seasoning, and therefore, the ASTA values of the ethoxyquin-spiked paprika seasoning samples were lower than those of the control group because their residual ethoxyquin levels decreased in time. These results confirmed that the oxidation of the carotenoids in paprika seasoning was effectively inhibited using $100 \mu \mathrm{g} / \mathrm{mL}$ ethoxyquin, which is the maximum allowable ethoxyquin limit in the USA.

\subsection{Measurement Uncertainty}

Method validation determines the reliability of the analytical results, however, validation is not sufficient for the accurate interpretation and comparison of the results [14]. The measurement uncertainty of ethoxyquin in paprika seasoning was assessed using the HPLC-PDA method. It was used as a parameter to confirm the uncertainty of the measurement and to evaluate the combined standard uncertainty based on the Guide to the Expression of Uncertainty in Measurement (GUM) and the Draft EURACHEM Guide [15-17]. The following individual sources of uncertainty were considered in this study: $U_{\text {prep }}, U_{R M}, U_{s t d}, U_{c a l}$, and $U_{\text {rep }}$. The uncertainty of the analytical equipment was obtained from the certificate of calibration and was evaluated for repeated tests at laboratory temperature. The $U_{\text {prep }}$ value was gauged using a $25 \mathrm{~mL}$ volumetric flask and chemical balance. A $25 \mathrm{~mL}$ volumetric flask was purchased from Marienfeld (UK). The volumetric flasks and equipment used in the measurement uncertainty experiment were regularly issued with calibration certificates, and the uncertainty was calculated using the values written on the calibration certificate. The uncertainty of the volumetric flask was determined using the information in the certificate of calibration $(0.007 \mathrm{~mL})$, repeatability $(0.00010 \mathrm{~mL})$, and changes in volume with the temperature $(0.021 \mathrm{~mL})$; moreover, the uncertainty of the chemical balance was determined using the information in the certificate of calibration $(0.0050 \mathrm{~g})$, stability $(0.000032 \mathrm{~g})$, and repeatability $(0.000029 \mathrm{~g})$. The relative standard uncertainties of the $25 \mathrm{~mL}$ volumetric flask and chemical balance were 0.000198 and 0.000888 , respectively. The combined $U_{\text {prep }}$ value was 0.000945 . The $U_{R M}$ value was determined according to the certificate of analysis of ethoxyquin. The $U_{s t d}$ value was determined using a $25 \mathrm{~mL}$ volumetric flask and a chemical balance. The uncertainty of the $25 \mathrm{~mL}$ volumetric flask was determined using the information in its certificate of calibration $(0.007 \mathrm{~mL})$, variation in volume with the temperature $(0.021 \mathrm{~mL})$, and repeatability $(0.00010 \mathrm{~mL})$; furthermore, the uncertainty of the chemical balance was determined as described above. The relative standard uncertainties of the $25 \mathrm{~mL}$ volumetric flask and chemical balance were 0.002594 and 0.000888 , respectively. The combined $U_{\text {std }}$ value was 0.002742 . The $U_{c a l}$ value of ethoxyquin was determined using seven ethoxyquin concentrations that were measured in triplicate. All uncertainties were calculated as the square root of the sum of the squares of each element.

The contributions of all uncertainty sources are summarized in Table 6, and $U_{c a l}$ presented the highest contribution to the overall uncertainty. The combined and expanded uncertainty, considering a confidence interval of approximately $95 \%$ and a coverage factor of 2 , was calculated for the standard used for calibration. The expanded uncertainty was confirmed to be 2.01 , which is within $5 \%$ of the final result, making it difficult to conclude that a certain factor is the main factor.

Table 6. Individual uncertainties of the sample preparation $\left(U_{\text {prep }}\right)$, reference material $\left(U_{R M}\right)$, standard stock solution $\left(U_{s t d}\right)$, calibration curve $\left(U_{c a l}\right)$, repeatability $\left(U_{r e p}\right)$, and expanded uncertainty $(U)$ in accordance with the EURACHEM Guide.

\begin{tabular}{ccccccc}
\hline Analytes & $U_{\text {prep }}$ & $U_{R M}$ & $U_{\text {std }}$ & $U_{\text {cal }}$ & $U_{\text {rep }}$ & $U$ \\
\hline Ethoxyquin & 0.0009 & 0.0064 & 0.0027 & 0.0234 & 0.0040 & 2.01 \\
\hline
\end{tabular}




\section{Conclusions}

In this study, the validation of the HPLC-PDA method for the quantitative analysis of ethoxyquin from paprika seasoning and sauce were assessed. The analytical method for the detection of ethoxyquin was assessed according to the ICH guidelines, and it was concluded that the validated HPLC-PDA method was suitable for the quantitative analysis of ethoxyquin from paprika seasoning and sauce. The validated method was used to evaluate real-life samples, and the presence of ethoxyquin was not detected in any of the analyzed samples. In addition, a functional evaluation of ethoxyquin was performed to assess its antioxidant activity by determining the ASTA values and residual ethoxyquin levels in paprika samples during storage. The obtained results confirmed that the validated method was reasonable for the identification and quantification of ethoxyquin and could be used to assess the safety of ethoxyquin-containing paprika seasoning and sauce. In addition, the functional evaluation of ethoxyquin allowed us to conclude that ethoxyquin could be effectively used as an antioxidant.

Author Contributions: Methodology, G.-W.J., S.-I.C., X.H., and O.-H.L.; validation, G.-W.J. and S.-I.C.; resources, X.H.; data curation, X.M., H.-Y.K., Y.-E.C., and M.-H.P.; writing-original draft preparation, G.-W.J. and S.-I.C.; writing-review and editing, G.-W.J., S.-I.C. and O.-H.L.; supervision, O.-H.L.; project administration, O.-H.L.; funding acquisition, O.-H.L. All authors have read and agreed to the published version of the manuscript.

Funding: This work was supported by the Basic Science Research Program through the National Research Foundation of Korea (NRF) funded by the Ministry of Education [grant number NRF, 2017R1D1A3B06028469], the National Research Foundation of Korea (NRF) funded by the Korean Government [grant number 2020-D-G035-010108], and Global Ph.D Fellowship Program through the NRF funded by the Ministry of Education [grant number NRF, 2018H1A2A1062634].

Conflicts of Interest: The authors declare no conflict of interest.

\section{References}

1. Lee, S.O.; Lee, S.K.; Kyung, S.H.; Park, G.D.; Kang, H.G.; Park, J.S. Pigment stability of paprika extract, detection of ethoxyquin and residual solvent. Appl. Biol. Chem. 2002, 45, 77-83.

2. Osuna-Garcia, J.A.; Marisa, M.; Wall, M.M.; Waddell, C.A. Natural antioxidants for preventing color loss in stored paprika. J. Food Sci. 1997, 62, 1017-1021. [CrossRef]

3. Biacs, P.; Daood, H.; Huszka, T. Biochemical and varietal perspective on the color loss in spice red pepper (paprika). Hung Agric. Res. 1994, 3, 32-37.

4. He, P.; Ackman, R.G. Residues of ethoxyquin and ethoxyquin dimer in ocean-farmed salmonids determined by high-pressure liquid chromatography. J. Food Sci. 2000, 65, 1312-1314. [CrossRef]

5. Chen, S.L.; Gutmanis, F. Auto-oxidation of extractable color pigments in chili pepper with special reference to ethoxyquin treatment. J. Food sci. 1968, 33, 274-280. [CrossRef]

6. Quattrucci, B.E. International symposium on current issues with food preservatives. In International Symposium on Current Issues with Food Preservatives: Chemico-Technical, Nutritional and Safety in Use Aspects; National Institute of Nutrition: Rome, Italy, 1992.

7. FDA. Code of Federal Regulations (CFR) title 21: Food and drugs; National Archives and Records Administration, Office of the Federal Register: Washington, DC, USA, 2020; Volume 9.

8. Lee, J.S.; Kim, Y.H.; Kim, J.M.; Kang, S.R.; Lee, C.; Shin, J.W.; Chun, H.S.; Lee, O.H. Current permitted status and management system of food additives in the inside and outside of the country. Korean J. Food Sci. Technol. 2014, 47, 46-53.

9. Kato, S.; Kanohta, K. Chromatographic studies of the autoxidation products of ethoxyquin and its photochemical conversion. J. Chromatogr. A. 1985, 324, 462-468. [CrossRef]

10. Vinas, P.; Cordoba, M.H.; Sanchez-Pedreno, C. Determination of ethoxyquin in paprika by high-performance liquid chromatography. Food Chem. 1991, 42, 241-251. [CrossRef]

11. International Conference on Harmonization (ICH). International Conference on Harmonization of Technical Requirements for Registration of Pharmaceuticals for Human Use ICH Harmonised Tripartite Guidline. Validation of Analytical Procedures: Text and Methodology. Available online: https://www.ich.org/fileadmin/ Public_Web_Site/ICH_Products/Guidelines/Quality/Q2_R1/Step4/Q2_R1_Guideline.pdf (accessed on 8 September 2020). 
12. ASTA. The Voice of the U.S. Spice Industry in the Global Market. Available online: http://www.astaspice.org/ food-safety/astas-analytical-methods-manual/ (accessed on 26 November 2017).

13. Kim, J.M.; Choi, S.H.; Shin, G.H.; Lee, J.H.; Kang, S.R.; Lee, K.Y.; Lim, H.S.; Kang, T.S.; Lee, O.H. Method validation and measurement uncertainty for the simultaneous determination of synthetic phenolic antioxidants in edible oils commonly consumed in Korea. Food Chem. 2016, 213, 19-25. [CrossRef] [PubMed]

14. Rozet, E.; Marini, R.D.; Ziemons, E.; Boulanger, B.; Hubert, P. Advances in validation, risk and uncertainty assessment of bioanalytical methods. J. Pharm. Biomed. Anal. 2011, 55, 848-858. [CrossRef] [PubMed]

15. ISO. ISO 98-3 Guide to the Expression of Uncertainty in Measurements; International Organization for Standardization: Geneva, Switzerland, 1995.

16. NIST. NIST Guideline for Evaluating and Expressing the Uncertainty of NIST Measurement Results; National Institute of Standards and Technology: Gaithersburg, MD, USA, 1993.

17. Eurachem. Quantifying Uncertainty in Analytical Measurement, 3rd ed. Available online: https://www. eurachem.org/index.php/publications/guides/quam (accessed on 8 September 2020).

(C) 2020 by the authors. Licensee MDPI, Basel, Switzerland. This article is an open access article distributed under the terms and conditions of the Creative Commons Attribution (CC BY) license (http://creativecommons.org/licenses/by/4.0/). 